\title{
Ets-1 transcription factor is widely expressed in benign and malignant melanocytes and its expression has no significant association with prognosis
}

\author{
Emina E Torlakovic ${ }^{1,2}$, Nurija Bilalovic ${ }^{3}$, Jahn M Nesland ${ }^{1}$, Goran Torlakovic ${ }^{1}$ and \\ Vivi A Flørenes ${ }^{1}$ \\ ${ }^{1}$ Department of Pathology, The Norwegian Radium Hospital University of Oslo, Oslo, Norway; ${ }^{2}$ Department of \\ Pathology, Royal University Hospital, University of Saskatchewan, Saskatoon, Canada and ${ }^{3}$ Department of \\ Pathology, University Hospital Sarajevo, Bosnia and Herzegovina
}

\begin{abstract}
Ets-1 transcription factor has been associated with tumor progression in various carcinomas, but its expression in malignant melanoma was only recently described. The study was conducted in two steps: exploratory and confirmatory. In the first step, we studied 69 primary melanomas, 28 metastatic melanomas, 10 usual intradermal nevi and 13 various melanocytic skin lesions. In the second step, an additional group of 98 patients with follow-up of up to $\mathbf{2 0 0}$ months was also evaluated. Immunohistochemical analysis of formalinfixed/paraffin-embedded tissues was performed using 1G11 antibody and polymer conjugate for visualization. While Ets-1 was variably expressed in $83 \%$ primary melanomas in exploratory and $69 \%$ in the confirmatory group, the expression of Ets-1 was also found in normal benign melanocytes and all nevi. Analysis of the exploratory group revealed lower expression of Ets-1 in primary melanomas than in common nevi $(P=0.048$, Mann-Whitney $U$-test) and metastatic melanomas expressed significantly less Ets- 1 than primary melanomas $(P=0.015$, Mann-Whitney $U$-test). There was a negative correlation between Ets-1 expression and the largest dimension of the primary tumors $(r=0.23, P=0.034$, Spearman's correlation rank test), but no correlation with the depth of tumor invasion (Breslow thickness) or the presence of ulceration was found. Analyses of the confirmatory group revealed no association between Ets-1 expression with disease-specific survival or time to treatment failure. However, a statistical trend was found for worse outcome for those primary melanomas that had strong expression $(H$-score $>100)$ of Ets-1 $(P=0.054)$. Ets-1 is expressed in benign melanocytes probably due to their neural crest origin. We conclude that Ets-1 expression cannot be used to differentiate between benign and malignant melanocytic lesions and it has no definite association with clinical outcome. At the same time, its role in tumor progression in some cases of malignant melanoma cannot be entirely excluded. Modern Pathology (2004) 17, 1400-1406, advance online publication, 18 June 2004; doi:10.1038/modpathol.3800206
\end{abstract}

Keywords: Ets-1; malignant melanoma; survival; neural crest

Malignant melanoma originates from melanocytes derived from the neural crest. ${ }^{1}$ It is the most deadly form of skin cancer, whose incidence is rapidly increasing worldwide. $^{2}$ To date the most reliable prognostic marker of malignant melanoma is the vertical thickness (Breslow thickness) of the primary tumor. $^{3,4}$ Although progression of malignant mela-

Correspondence: Dr EE Torlakovic, MD, Department of Pathology, Royal University Hospital, University of Saskatchewan, 103 Hospital Drive, Saskatoon, Canada SK S7N0W8.

E-mail: emina.torlakovic@saskatoonhealthregion.ca,

emina.torlakovic@mail.usask.ca

Received 27 November 2003; revised 6 April 2004; accepted 4 May 2004; published online 18 June 2004 noma occurs through a series of well-defined steps, the knowledge of genetic and phenotypic background for the disease is still rather scarce. The proto-oncogene ETS-1 belongs to the ETS family of transcription factors that also include, among others, ets-2, elf-1, fli-1 and PU-1. ${ }^{5-7}$ Ets-1 plays an important role in cancer progression due to its ability to activate transcription of metastasis-, angiogenesis- and invasion-associated genes. ${ }^{8-12}$

In a limited study on 10 melanomas and 24 benign melanocytic lesions, Keehn et $a l^{13}$ recently reported expression of the Ets-1 in melanocytic lesions and suggested that Ets-1 expression might be an important pathogenic mechanism and predictor of aggressive biologic behavior of cutaneous melanoma. 
Herein, we have investigated whether expression of Ets-1 differs through the spectrum of melanocytic lesions and whether its expression in primary melanoma is associated with disease-specific survival and time to treatment failure.

\section{Materials and methods}

In the first step, formalin-fixed, paraffin-embedded tissue sections from 69 primary melanomas, 28 metastatic melanomas, 10 usual intradermal nevi and 13 various melanocytic skin lesions (two Spitz nevi, one Halo nevus, two common blue nevi, one cellular blue nevus and seven dysplastic nevi with moderate atypia) were randomly collected from the archives of the pathology department, The Norwegian Radium Hospital. The median age of the patients was 62 years (range 19-93 years). Of the primary tumors, 53 were classified as superficial spreading and 15 as nodular. The primary tumor thickness median was $1.25 \mathrm{~mm}$ (range 0.30$7.00 \mathrm{~mm}$ ) for superficial spreading tumors and $3.9 \mathrm{~mm}$ (range $1.50-6.00 \mathrm{~mm}$ ) for nodular melanoma. The largest tumor dimension (diameter of the tumor) was also recorded.

In the second step, we included formalin-fixed/ paraffin-embedded tissues from additional 98 patients with median follow-up for patients alive of 156 months (range 68-200 months). In total, 62 were classified as superficial spreading and 36 as nodular melanomas. The median age was 54 years (range 25-83 years). For superficial spreading tumors, the median tumor thickness was $1.20 \mathrm{~mm}$ (range $0.11-$ $10.00 \mathrm{~mm}$ ), whereas the mean depth of nodular tumors was $4.00 \mathrm{~mm}$ (range $1.23-15.00 \mathrm{~mm}$ ). Overall, the mean depth of invasion was $2.88 \mathrm{~mm}$ (range 0.11-15.00 mm). Treatment of patients was according to WHO standard guidelines.

\section{Immunohistochemistry}

Formalin-fixed, paraffin-embedded tissue was cut at $5 \mu \mathrm{m}$, dried overnight at $60^{\circ} \mathrm{C}$ and deparaffinized in xylene. Subsequently, sections were rehydrated through graded alcohols into water. Heat-induced epitope retrieval was achieved by boiling sections in the EDTA buffer at $\mathrm{pH} 8.9$ in the Electrolux microwave oven (Stockholm, Sweden) at $1000 \mathrm{~W}$ for $20 \mathrm{~min}(4 \times 5 \mathrm{~min})$. After boiling, sections were allowed to cool at room temperature for $20 \mathrm{~min}$, rinsed thoroughly with water and placed in Trisbuffered saline (TBS) for 5 min. Endogenous peroxidase was blocked with peroxidase block solution provided in the EnVison $+{ }^{\circledR}$ kit (DakoCytomation, Glostrup, Denmark) for $5 \mathrm{~min}$ and slides rinsed/ washed with TBS. Slides were then incubated with 1G11 antibody (1:20, NovoCastra Laboratories, New Castle upon Tyne, UK) for $30 \mathrm{~min}$ at room temperature. Visualization was performed using EnVision $+{ }^{\mathbb{B}}$ (DakoCytomation, Glostrup, Denmark) method according to the manufacturer's instructions. Appropriate positive and negative controls were used. In addition, strong nuclear staining in benign small lymphocytes was used as internal positive control.

Only nuclear staining was recorded. Very faint cytoplasmic staining was also detected in some cases, but was not recorded. Ets-1 immunostaining showed great variability from case to case and in some cases, there was some variability in different areas of the tumor, but there was no definite order in the distribution of the positive cells with respect to horizontal or vertical orientation. Expression of Ets-1 was quantified using $H$-score (histo-score) system, according to the method described by McCarty et $a{ }^{14}{ }^{14}$ which considers both the intensity and percentage of cells staining at each intensity. Cells were counted using $\times 400$ magnification and a cell counter. The score was calculated as follows: $H$-score $=$ $(\% 3+$ cells $\times 3)+(\% 2+$ cells $\times 2)+(\% 1+$ cells $\times 1)$. Overall, the cases were also designated as 'positive' if more than $10 \%$ of the tumor cells showed expression of the antigen.

\section{Statistical Methods}

Disease-specific survival for the patients with 'Ets-1positive' vs 'Ets-1-negative' primary melanomas was calculated by the Kaplan-Meier survival estimates and the log-rank test from the date of diagnosis until last contact or death from disease. Time to treatment failure (TTF) was calculated from the date of first complete remission to the date of last contact, if alive and none relapsed, or to relapse or death, whichever came first. Results obtained by $H$-score were also analyzed by using the Cox proportional hazards model. The $\chi^{2}$, linear-to-linear association and Mann-Whitney $U$-tests were used whenever appropriate for comparison of subgroups. The association between the intensity of expression with depth of invasion (Clark levels); tumor thickness according to Breslow and diameter of tumors was studied with the Spearman rank correlation. Statistical significance was established at the $P<0.05$ level. Analyses were performed in SPSS 11.5.

\section{Results}

Results of the analysis of the exploratory group are summarized in Table 1. All common intradermal nevi and dysplastic nevi expressed high levels of Ets-1. The percent of positive cells was larger than $80 \%$ in all nevi. Similar Ets-1 expression was also found in Halo nevus and Spitz nevi, while blue nevi had comparable numbers of cells positive, but the intensity of the staining was less pronounced. Ets-1 was also expressed in benign intraepidermal melanocytes (Figure 1). Primary melanomas had lower expression of Ets-1 than common nevi $(P=0.048$, Mann-Whitney $U$-test) and metastatic melanomas 
Table 1 Ets-1 expression in benign and malignant melanocytic lesions (exploratory group, $n=120$ )

\begin{tabular}{lcccc}
\hline \multirow{2}{*}{ Ets-1 } & \multicolumn{3}{c}{ Diagnosis } \\
\cline { 2 - 5 } & Common intradermal nevus & Dysplastic nevus & Primary melanoma & Metastatic melanoma \\
\hline Negative & 0 & 0 & $12(17)$ & $9(32)$ \\
Positive & $10(100)$ & $7(100)$ & $57(83)$ & $19(68)$ \\
Total & $10(100)$ & $7(100)$ & $69(100)$ & $28(100)$ \\
\hline
\end{tabular}

Primary melanoma vs common nevi $(P=0.048$, Mann-Whitney $U$-test $)$ and primary melanomas vs metastatic melanoma $(P=0.015$, MannWhitney $U$-test).
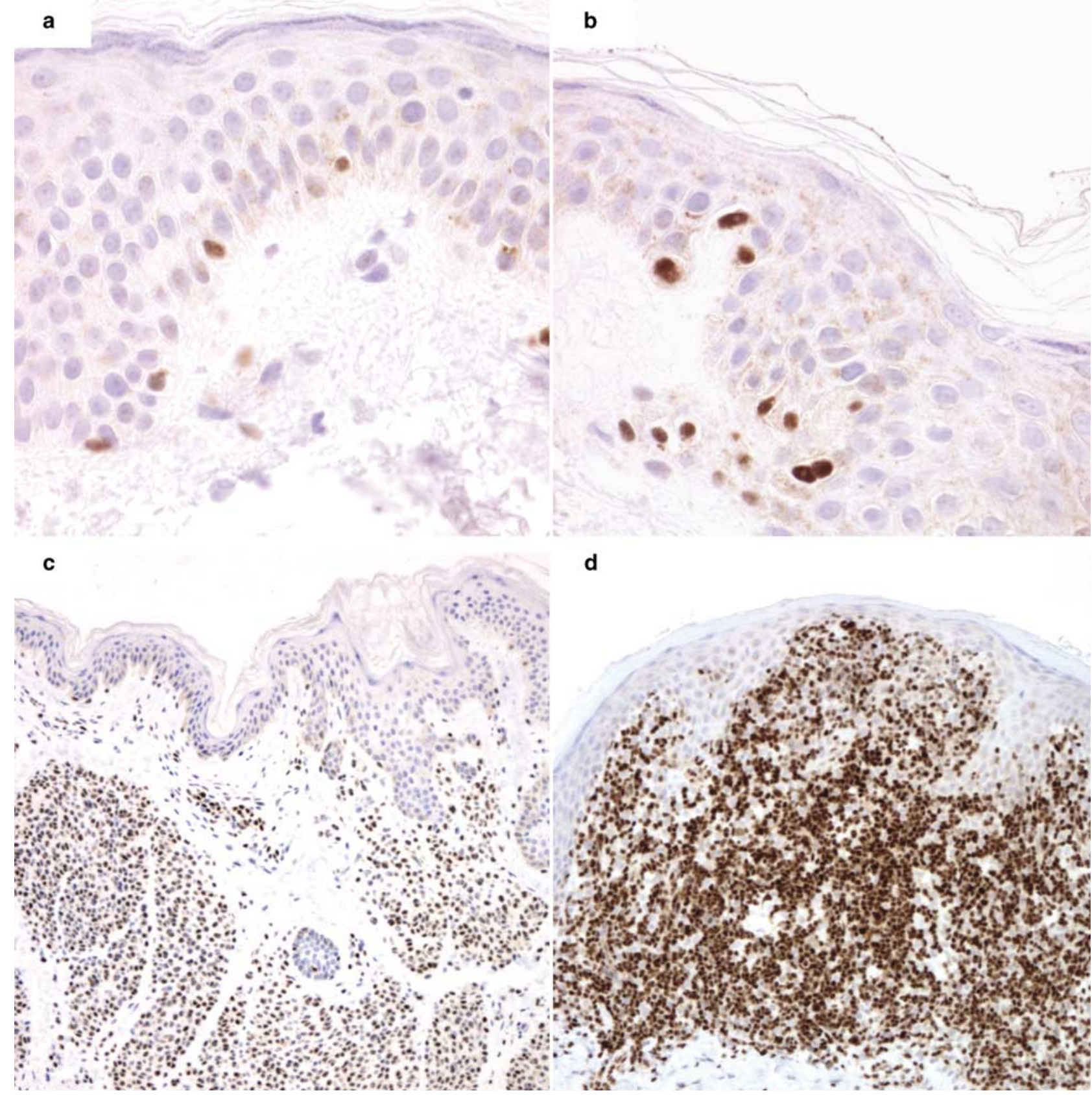

d

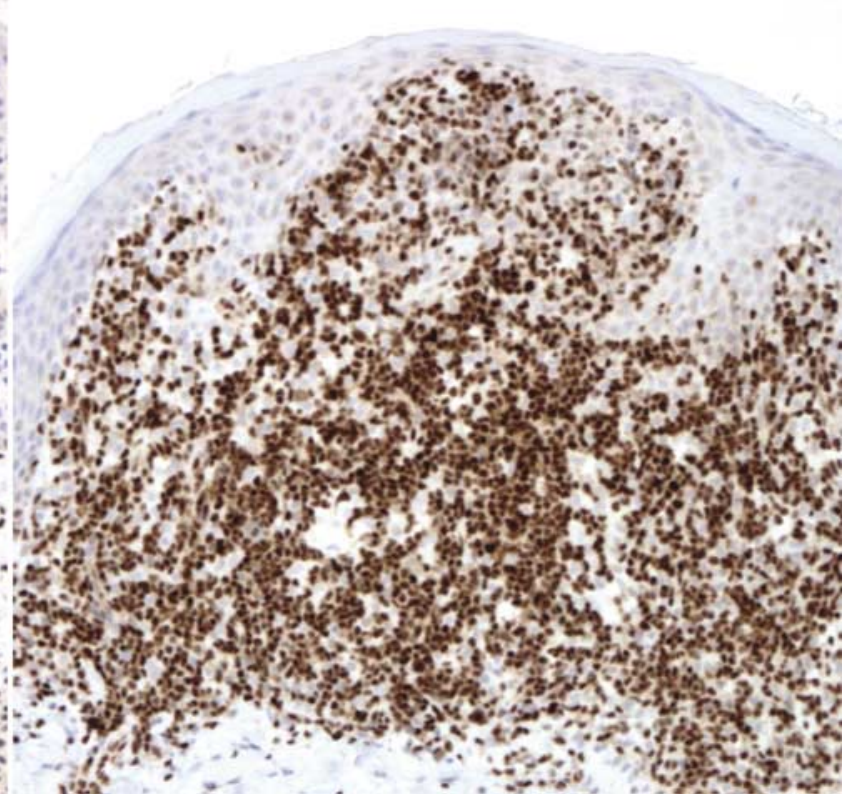

Figure 1 Intraepidermal benign melanocytes show variable expression of Ets-1. Some have weak (a) and some strong (b) expression ( $\times 400$ magnification). Usual benign nevi have moderate to strong expression. Intraepidermal nevus (c) and Halo nevus (d) are shown ( $\times 200$ magnification) (Ets-1 immunostaining). 


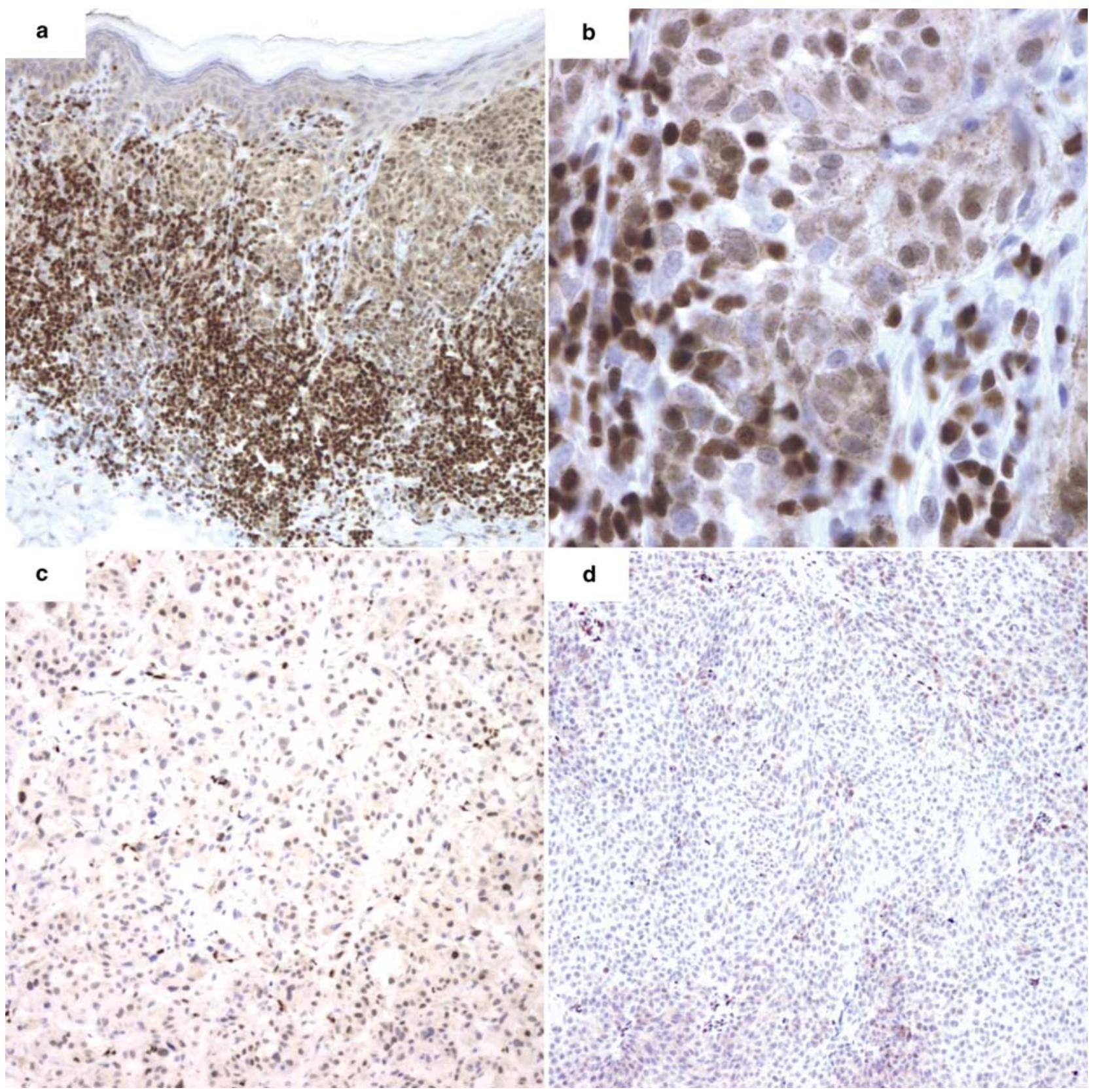

Figure 2 Strong expression of Ets-1 is present in peritumoral lymphocytes, while primary melanoma expresses weak to moderate Ets-1 (a) ( $\times 200$ magnification), (b) ( $\times 400$ magnification). Overall, expression of Ets-1 was much lower in metastatic melanoma as shown in the two representative cases (c and $\mathbf{d}$ ) ( $\times 400$ magnification) (Ets-1 immunostaining).

expressed significantly less Ets-1 than primary melanomas $(P=0.015$, Mann-Whitney $U$-test $)$ (Figure 2). There was a negative correlation between Ets-1 expression and diameter of the primary tumors $(r=0.23, P=0.034$, Spearman's correlation rank test), but no correlation with depth of tumor invasion or the presence of ulceration was found.

Results of the analysis of the confirmatory group are summarized in Table 2 and survival plots (Figures 3-5). The group of the patients, which was evaluated for the outcome, had $69 \%$ tumors with Ets-1 expression, which was similar to $83 \%$ in the exploratory group. No difference in diseasespecific survival was found between patients with Ets-1-positive and Ets-1-negative malignant primary melanoma $(P=0.98$, Kaplan-Mayer log-rank test) (Figure 3). However, patients with tumors that had high expression of Ets-1 ( $H$-score $>100$ ) showed a trend for shorter disease-specific survival $(P=0.054)$, but not for the TTF $(P=0.81)$ (Figure 4). Also, an association of older age ( $>65$ years) and shorter disease-specific survival $(P<0.0001)$ and TTF $(P=0.049)$ was found (Figure 5$)$. 
Table 2 Ets-1 expression in malignant melanoma (confirmatory group, $n=98)^{\mathrm{a}}$

\begin{tabular}{|c|c|c|c|}
\hline \multirow[t]{2}{*}{ Variable } & \multicolumn{2}{|c|}{ Ets-1 (\%) } & \multirow[t]{2}{*}{ Total } \\
\hline & Positive & Negative & \\
\hline \multicolumn{4}{|l|}{ Age (in years) } \\
\hline $25-45$ & $8(27)$ & $22(73)$ & $30(100)$ \\
\hline $46-65$ & $17(38)$ & $28(62)$ & $45(100)$ \\
\hline $66-83$ & $5(22)$ & $18(78)$ & $23(100)$ \\
\hline \multicolumn{4}{|l|}{ Sex } \\
\hline Male & $11(28)$ & $29(72)$ & $40(100)$ \\
\hline Female & $19(33)$ & $39(67)$ & $58(100)$ \\
\hline \multicolumn{4}{|l|}{ Туре } \\
\hline Superficial Spreading & $16(26)$ & $46(74)$ & $62(100)$ \\
\hline Nodular & $14(39)$ & $22(61)$ & $36(100)$ \\
\hline \multicolumn{4}{|l|}{ Depth of invasion ${ }^{\mathrm{b}}$} \\
\hline$<2.88 \mathrm{~mm}$ & $21(30)$ & $49(70)$ & $70(100)$ \\
\hline$\geq 2.88 \mathrm{~mm}$ & $9(33)$ & $18(67)$ & $27(100)$ \\
\hline \multicolumn{4}{|l|}{ Ulceration } \\
\hline No & $19(31)$ & $43(69)$ & $62(100)$ \\
\hline Yes & $8(26)$ & $23(74)$ & $31(100)$ \\
\hline
\end{tabular}

${ }^{\mathrm{a}}$ No significant associations were found.

$\mathrm{b}_{2.88 \mathrm{~mm}}=$ mean depth of invasion.

\section{Discussion}

The overexpression of Ets-1 found in different human cancers has been associated with invasiveness and the degree of malignancy. ${ }^{15-17}$ Ets-1 expression is not restricted to the tumor cells since its mRNA is also found in the stromal fibroblasts of invasive tumors. ${ }^{18,19}$ Ets-1 is not expressed in quiescent endothelial cells in adult tissues, but it is induced by proliferating and migrating endothelial cells but not after these cells have reached confluence. $^{20,21}$ The transcription factor Ets-1 is expressed in many different migratory cell types, suggesting that it may play an important role in regulating motility. Even though it was only recently described in melanomas, ${ }^{13}$ Ets- 1 is upregulated in the cranial neural folds and dorsal neural tube approximately $4-6 \mathrm{~h}$ prior to commencement of neural crest migration and continues to be expressed by migrating cranial neural crest cells and subsequently by some neural crest-derived tissues. ${ }^{22,23}$ Ets-1 was also demonstrated in the neural crest of the mouse embryo. ${ }^{24}$ Hence, the expression of Ets-1 in intraepidermal benign melanocytes is consistent with their neural crest origin and perhaps does not suggest neoplastic transformation in melanocytic lesions. Lower expression of Ets-1 in melanoma than in nevi as well as lower expression in metastatic than in primary tumors may suggest partial loss of the neural crest phenotype. Similarly, c-KIT, a tyrosine kinase receptor encoded by the c-KIT proto-oncogene, has been found to play a pivotal role in normal growth and differentiation of
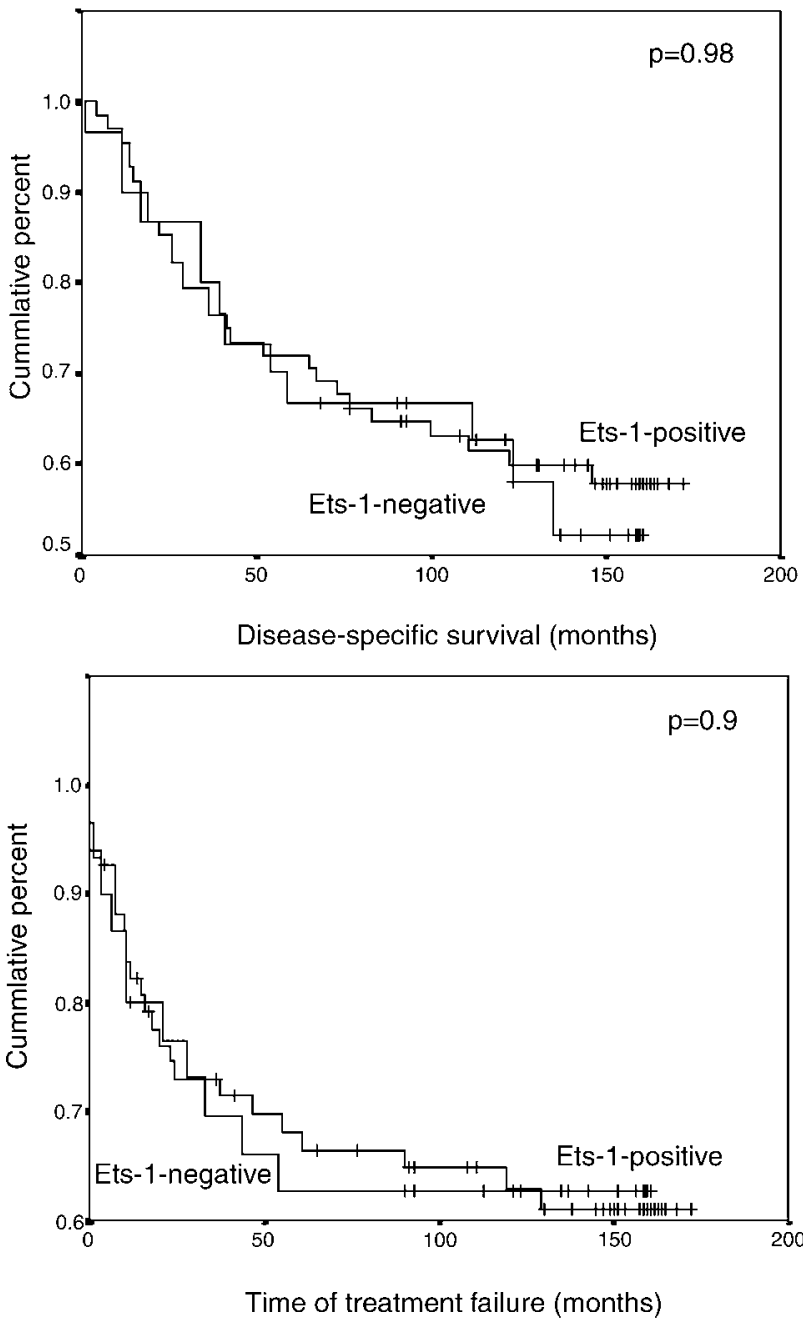

Figure 3 No difference in disease-specific survival or TTF is found between cases with or without Ets-1 expression.

embryonic melanoblasts, but its expression progressively decreases during local tumor growth and invasion of human melanomas. ${ }^{25-27}$ Of note, another transcription factor, AP-2, which is also expressed in neural crest cell lineages during mouse embryogenesis, was found to be downregulated in malignant melanoma. ${ }^{28}$ Loss of AP-2 correlated with loss of c-KIT expression in highly metastatic melanoma cells. ${ }^{29}$ Furthermore, loss or inactivation of the p16 gene, the product of the p16/INK4a/CDKN2/MTS tumor suppressor gene, has been shown to be associated with the progression of melanoma. ${ }^{30}$ It has been recently reported that Ets-1 as well as Ets-2 activate the promoter of the p16 INK4a gene, whose product inhibits Cdk4 and Cdk6 cyclin-dependent kinases, through an Ets-binding site and contributes to regulation of cellular senescence. ${ }^{31}$ Our findings are in agreement with these previous studies.

Huang et $a l^{32}$ were able to inhibit melanoma growth and metastasis by enforced c-KIT expression implying that downregulation of c-KIT is related to melanoma progression. Downregulation of Ets-1 

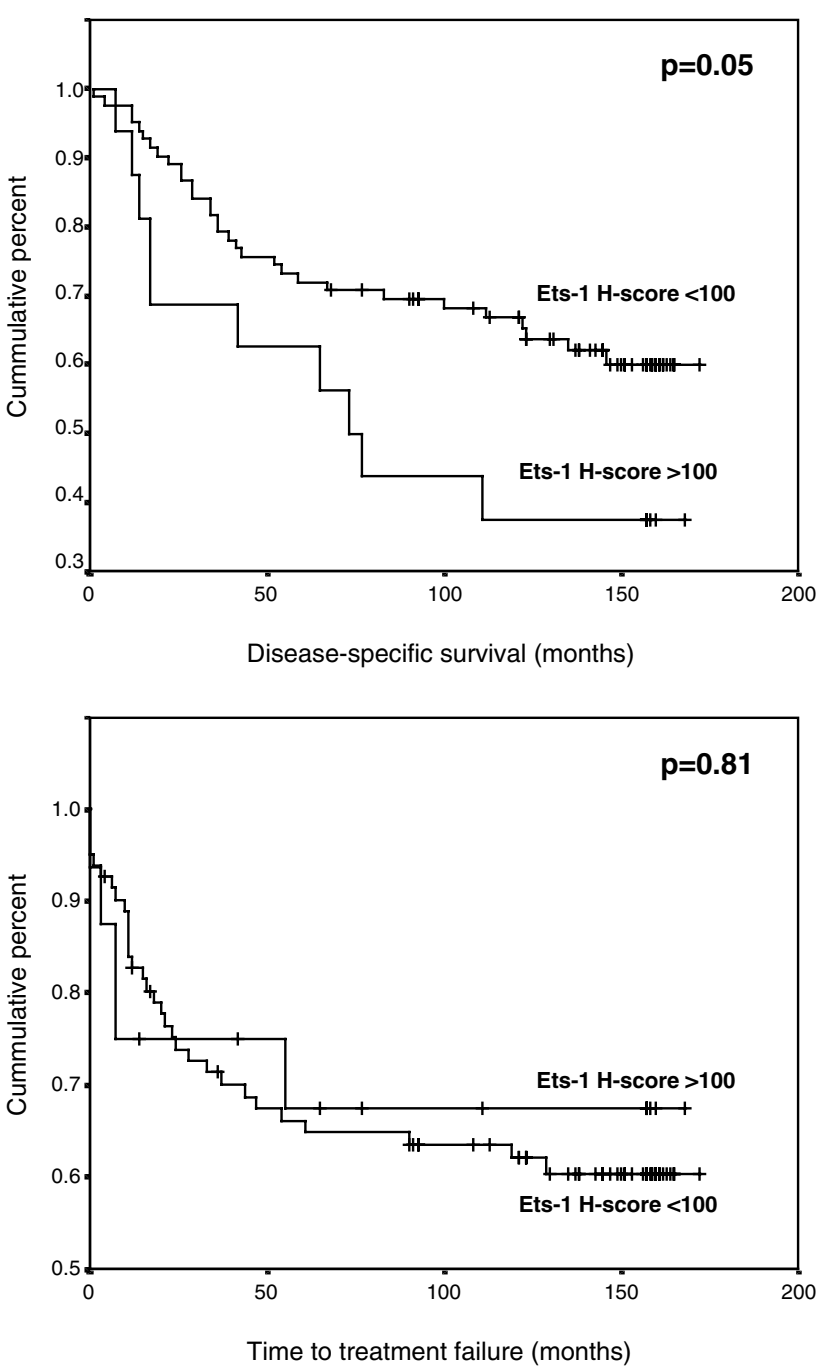

Figure $4 \mathrm{~A}$ trend for shorter disease-specific survival was found for the primary melanomas with strong expression of Ets-1.

does not appear to have the same connotation because we found a statistical trend showing that primary melanomas with strong expression of Ets-1 have worse outcome. This finding suggests multifactorial role of Ets-1 in biology of malignant melanoma. It cannot be excluded that Ets-1 still may have an important function in aggressive melanomas by its role in angiogenesis and tumor invasion by regulation of genes encoding for enzymes involved in degradation of the extracellular matrix. ${ }^{33-35}$ Our finding that older age is a strong negative prognostic factor in malignant melanoma is also in agreement with previously published studies. ${ }^{36,37}$

\section{References}

1 Herlyn M, Berking C, Li G, et al. Lessons from melanocyte development for understanding the biolo-
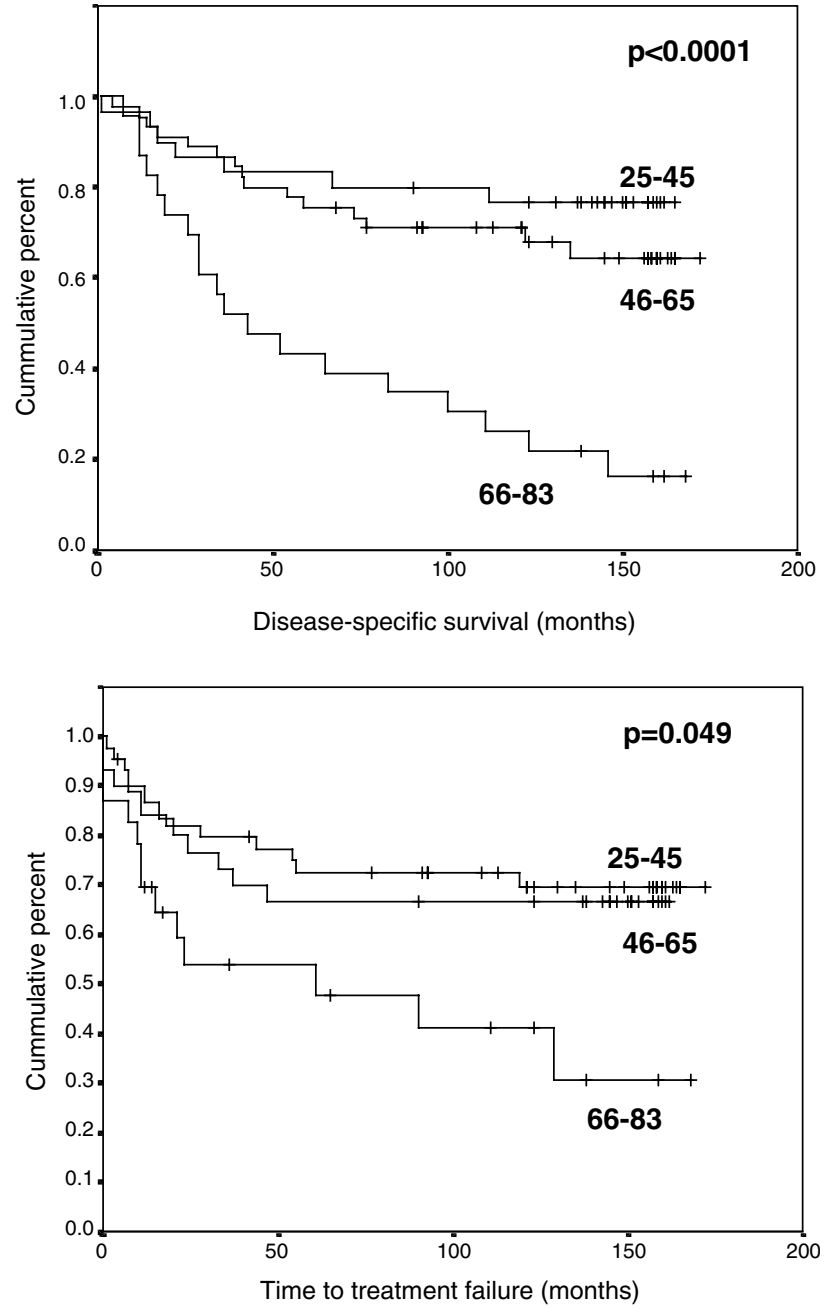

Figure 5 Older age is a strong negative prognostic factor in malignant melanoma.

gical events in naevus and melanoma formation. Melanoma Res 2000;10:303-312.

2 Bastuji-Garin S, Diepgen TL. Cutaneous malignant melanoma, sun exposure, and sunscreen use: epidemiological evidence. Br J Dermatol 2002;146(Suppl 61): $24-30$

3 Breslow A. Tumor thickness, level of invasion and node dissection in stage I cutaneous melanoma. Ann Surg 1975;182:572-575.

4 Marghoob AA, Koenig K, Bittencourt FV, et al. Breslow thickness and Clark level in melanoma: support for including level in pathology reports and in American Joint Committee on Cancer Staging. Cancer 2000;88: 589-595.

5 Wasylyk B, Hagman J, Gutierrez-Hartmann A. Tumor suppressor p53 inhibits transcriptional activation of invasion gene thromboxane synthase mediated by the proto-oncogenic factor Ets-1. Oncogene 2003;22: 7716-7727.

6 Pastorcic M, Das HK. Regulation of transcription of the human presenilin-1 gene by Ets transcription factors and the p53 protooncogene. J Biol Chem 2000;275: 34938-34945.

7 Wasylyk C, Schlumberger SE, Criqui-Filipe P, et al. Sp100 interacts with ETS-1 and stimulates its 
transcriptional activity. Mol Cell Biol 2002;22: 2687-2702.

8 Watabe T, Yoshida K, Shindoh M, et al. The Ets-1 and Ets-2 transcription factors activate the promoters for invasion-associated urokinase and collagenase genes in response to epidermal growth factor. Int J Cancer 1998;77:128-137.

9 Valter MM, Hugel A, Huang HJ, et al. Expression of the Ets-1 transcription factor in human astrocytomas is associated with Fms-like tyrosine kinase-1 (Flt-1)/ vascular endothelial growth factor receptor-1 synthesis and neoangiogenesis. Cancer Res 1999;59:5608-5614.

10 Fenrick R, Wang L, Nip J, et al. TEL, a putative tumor suppressor, modulates cell growth and cell morphology of ras-transformed cells while repressing the transcription of stromelysin-1. Mol Cell Biol 2000;20: 5828-5839.

11 Behrens P, Rothe M, Wellmann A, et al. The Ets-1 transcription factor is up-regulated together with MMP 1 and MMP 9 in the stroma of pre-invasive breast cancer. J Pathol 2001;194:43-50.

12 Kita D, Takino T, Nakada M, et al. Expression of dominant-negative form of Ets-1 suppresses fibronectin-stimulated cell adhesion and migration through down-regulation of integrin alpha5 expression in U251 glioma cell line. Cancer Res 2001;61:7985-7991.

13 Keehn CA, Smoller BR, Morgan MB. Expression of the Ets-1 proto-oncogene in melanocytic lesions. Mod Pathol 2003;16:772-777.

14 McCarty Jr KS, Miller LS, Cox EB, et al. Use of a monoclonal anti-estrogen receptor antibody in the immunohistochemical evaluation of human tumors. Arch Pathol Lab Med 1985;109:716-721.

15 Nakada M, Yamashita J, Okada Y, et al. Ets-1 positively regulates expression of urokinase-type plasminogen activator (uPA) and invasiveness of astrocytic tumors. J Neuropathol Exp Neurol 1999;58:329-334.

16 Kitange $\mathrm{G}$, Tsunoda $\mathrm{K}$, Anda $\mathrm{T}$, et al. Immunohistochemical expression of Ets-1 transcription factor and the urokinase-type plasminogen activator is correlated with the malignant and invasive potential in meningiomas. Cancer 2000;89:2292-2300.

17 Jiang Y, Xu W, Lu J, et al. Invasiveness of hepatocellular carcinoma cell lines: contribution of hepatocyte growth factor, c-met, and transcription factor Ets-1. Biochem Biophys Res Commun 2001;286:1123-1130.

18 Wernert N, Gilles F, Fafeur V, et al. Stromal expression of c-Ets-1 transcription factor correlates with tumor invasion. Cancer Res 1994;54:5683-5688.

19 Vandenbunder B, Queva C, Desbiens X, et al. Expression of the transcription factor c-Ets-1 correlates with the occurrence of invasive processes during normal and pathological development. Invas Metast 1994-95; 14:198-209.

20 Wernert N, Raes MB, Lassalle P, et al. c-Ets-1 protooncogene is a transcription factor expressed in endothelial cells during tumor vascularization and other forms of angiogenesis in humans. Am J Pathol 1992; 140:119-127.

21 Tanaka K, Oda N, Iwasaka C, et al. Induction of Ets-1 in endothelial cells during reendothelialization after denuding injury. J Cell Physiol 1998;176:235-244.
22 Vandenbunder B, Pardanaud L, Jaffredo $\mathrm{T}$, et al. Complementary patterns of expression of c-ets 1, c-myb and c-myc in the blood-forming system of the chick embryo. Development 1989;107:265-274.

23 Tahtakran SA, Selleck MA. Ets-1 expression is associated with cranial neural crest migration and vasculogenesis in the chick embryo. Gene Expr Patterns 2003;3:455-458.

24 Maroulakou IG, Papas TS, Green JE. Differential expression of ets-1 and ets-2 proto-oncogenes during murine embryogenesis. Oncogene 1994;9:1551-1565.

25 Lassam N, Bickford S. Loss of c-kit expression in cultured melanoma cells. Oncogene 1992;7:51-56.

26 Natali PG, Nicotra MR, Winkler AB, et al. Progression of human cutaneous melanoma is associated with loss of expression of c-kit proto-oncogene receptor. Int J Cancer 1992;52:197-201.

27 Zakut R, Perlis R, Eliyahu S, et al. KIT ligand (mast cell growth factor) inhibits the growth of KIT-expressing melanoma cells. Oncogene 1993;8:2221-2229.

28 Mitchell PJ, Timmons PM, Hebert JM, et al. Transcription factor AP-2 is expressed in neural crest cell lineages during mouse embryogenesis. Genes Dev 1991;5:105-119.

29 Huang S, Jean D, Luca M, et al. Loss of AP-2 results in downregulation of c-KIT and enhancement of melanoma tumorigenicity and metastasis. EMBO J 1998;17: 4358-4369.

30 Reed JA, Loganzo Jr F, Shea CR, et al. Loss of expression of the p16/cyclin-dependent kinase inhibitor 2 tumor suppressor gene in melanocytic lesions correlates with invasive stage of tumor progression. Cancer Res 1995;55:2713-2718.

31 Ohtani N, Zebedee Z, Huot TJ, et al. Opposing effects of Ets and Id proteins on p16INK4a expression during cellular senescence. Nature 2001;409:1067-1070.

32 Huang S, Luca M, Gutman M, et al. Enforced c-KIT expression renders highly metastatic human melanoma cells susceptible to stem cell factor-induced apoptosis and inhibits their tumorigenic and metastatic potential. Oncogene 1996;13:2339-2347.

33 Naito S, Shimizu S, Matsuu M, et al. Ets-1 upregulates matrix metalloproteinase-1 expression through extracellular matrix adhesion in vascular endothelial cells. Biochem Biophys Res Commun 2002;291:130-138.

34 Ozaki I, Mizuta T, Zhao G, et al. Involvement of the Ets-1 gene in overexpression of matrilysin in human hepatocellular carcinoma. Cancer Res 2000;60: 6519-6525.

35 Watabe T, Yoshida K, Shindoh M, et al. The Ets-1 and Ets-2 transcription factors activate the promoters for invasion-associated urokinase and collagenase genes in response to epidermal growth factor. Int J Cancer 1998;77:128-137.

36 Averbook BJ, Fu P, Rao JS, et al. A long-term analysis of 1018 patients with melanoma by classic Cox regression and tree-structured survival analysis at a major referral center: implications on the future of cancer staging. Surgery 2002;132:589-602.

37 Austin PF, Cruse CW, Lyman G, et al. Age as a prognostic factor in the malignant melanoma population. Ann Surg Oncol 1994;1:487-494. 